\title{
Circulação de saberes entre instituições: um caminho para decolonização da didática da Matemática
}

\author{
Domingos Arcanjo Antonio Nhampinga ${ }^{1}$ (iD \\ Universidade Púnguè / Universidade Federal da Bahia \\ Luiz Marcio Santos Farias ${ }^{2}$ iD \\ Universidade Federal da Bahia-Instituto de Humanidades, Artes e Ciências Prof. \\ Milton Santos (IHAC) \\ Dossiê | Dossier | Dosier \\ DOI do artigo: 10.22481/odeere.v6i2.9809
}

\begin{abstract}
RESUMO
O presente artigo insere-se no quadro da Didática da Matemática (DM), alicerçando na Teoria Antropológica do didático (TAD), uma teoria que tem o objeto de saber como seu foco, analisandoo a nível epistemológico e institucional e tem entre os seus elementos primitivos de analise, a abordagem ecologia, praxeológica e a noção de relação ao objeto. É sobre a relação ao objeto que o artigo concentra a sua discussão, a nível teórico, objetivando mostrar como a DM pode contribuir para um debate sobre a decolonização epistemológica de saberes no ensino da Matemática. Em nossa analise, destacamos a abordagem ecológica como o principal elemento de análise na TAD que, ao se situar na análise das condições e restrições de vida do objeto em seu ambiente conceitual, procura compreender como o objeto está posto nos currículos, ao questionar sobre o que existe? o que não existe? o que desapareceu e porquê? o que existe em outros ambientes de vida e não estão aqui? Porque que não estão qqui? Ełc. A DM procura por este meio, questionar e denunciar as práticas de ensino que tem as epistemologias do pensamento moderno colonial, eurocêntrico/ocidental como únicas formas de produção do conhecimento matemático, e que por via disso, tendem a subjugar, subalternizar, primitivizar sabedorias outras, não eurocêntricas/ocidentais. Ao mesmo tempo que denuncia, por meio da abordagem praxeológica, propõe ações, mecanismos que possibilitem trazer e discutir as sabedorias não eurocêntricas/ocidentais em espaços escolares, para participarem do processo de produção do conhecimento científico, através do processo de circulação de saberes ou praxeologias entre instituições.
\end{abstract}

Palavras-chave: Teoria Antropológica do Didático. Circulação de praxeologias. Decolonização didática.

\section{Circulation of knowledge between institutions: a path towards decolonization of the didactics of mathematics}

\begin{abstract}
The present article falls within the framework of the Didactics of Mathematics (DM), based on the Anthropological Theory of Didactics (ATD), a theory that has the object of knowledge as its focus, analyzing it at the epistemological and institutional level and has among its primary elements of analysis, the ecology, praxeological approach and the notion of relation to the object. It is on the object relation that the article concentrates its discussion, at the theoretical level, aiming to show how DM can contribute to a debate about the epistemological decolonization of knowledge in mathematics teaching. In our
\end{abstract}

1 Moçambicano, natural da província da Zambézia, distrito de Mopeia, nascido a 02/02/1987. Doutorando em Ensino, Filosofa e História da Ciência pela Universidade Federal da Bahia em cooperação com a Universidade Estadual de Feira de Santana - Brasil. Mestre em Estatística (2016) pela Universidade Pedagógica - Maputo/Moçambique em cooperação com a Universidade Complutense de Madrid Espanha. Bacharel (2010) e licenciado (2011) em Ensino de Matemática pela universidade Pedagógica - Quelimane/Moçambique. Docente da Universidade Púnguè - Extensão de Tete desde 2019. Foi docente da Universidade Pedagógica - Delegação de Tete (2012 - 2019). E-mail: daanhampinga@gmail.com 2 Professor do Instituto de Humanidades, Artes e Ciências Prof. Milton Santos (IHAC), Coordenador do Bacharelado Interdisciplinar em Ciência e Tecnologia-IHAC, da Universidade Federal da Bahia-UFBA, da Faculdade de Educação da UFBA e do Programa de Pós-Graduação em Ensino, Filosofia e História das Ciências da UFBA/UEFS, do qual foi coordenador de 2014 a 2016 e de 2016 a 2018. Graduado em Matemática (UFBA/UCSAL), Pós-graduado em Didática e Metodologia do Ensino Superior (EEAB), Mestre (UJF-França) e Doutor (UM2-França) em Didática das Ciências e Matemática. E-mail: Imsfarias@ufba.br 
analysis, we highlight the ecological approach as the main element of analysis in ATD, which, by placing itself in the analysis of the conditions and constraints of the object's life in its conceptual environment, seeks to understand how the object is placed in the curricula, by questioning what exists? what does not exist? what has disappeared and why? what exists in other life environments and are not here? Why aren't they here? Etc. DM tries, by this means, to question and denounce the teaching practices that have the epistemologies of modern, colonial, Eurocentric/Western thinking as the only ways of producing mathematical knowledge, and that, as a result, tend to subjugate, subordinate, primitivize other, nonEurocentric/Western knowledges. At the same time, it denounces, through the praxeological approach, it proposes actions, mechanisms that make it possible to bring and discuss non-Eurocentric/Western knowledges in school spaces, to participate in the process of scientific knowledge production, through the process of circulation of knowledges or praxeologies between institutions.

Keywords: Anthropological Theory of Didactics. Circulation of praxeologies. Didactic decolonization.

\section{Submetido em: 30/10/2021 | Aceito em: 16/12/2021}

\section{Introdução}

A educação hoje, em vários países cuja as suas raízes socioculturais no passado foram subjugadas em detrimento das políticas colônias, tem estado preocupado na recuperação e/ou valorização dos saberes que vivem em diversos contextos socioculturais. O processo da colonização deixou marcas severas nas suas colônias, de tal modo que, o processo da descolonização se constituiu apenas do desmembramento político-administrativo, tornando os países livres e sub governação própria, porém, herdando uma forma de ser e estar caraterística das políticas dominantes ocidentais.

Dentre várias áreas de gestão e desenvolvimento desses países, a Educação foi e é ainda hoje orientada por princípios epistemológicos dessa classe dominante. Assim, tanto os currículos, como as políticas e práticas de ensino, continuam até hoje em grande medida, orientadas sob uma visão eurocêntrica, não permitindo uma maior visibilidade e importância dos saberes que vivem nas instituições 3 socioculturais locais e não eurocêntricas na construção e desenvolvimento do mundo. O ensino da Matemática, em particular, foi por muito tempo marcado pela reprodução fiel do pensamento moderno colonial, das formas ocidentais e eurocêntricas de produção de conhecimento matemático escolar, caraterizado

3 Neste trabalho, compreendemos uma instituição sub olhar da TAD. Assim, conforme Chevallard (2018b), uma instituição é um dispositivo social que permite e impõe aos sujeitos que ocupam diferentes posições nela, implementam maneiras de fazer e pensar próprias. Pode ser então, uma sala de aulas, um livro didáctico, uma instituição de ensino, um contexto sociocultural, dentre outras. Aqui, o termo instituição não tem é utilizada de forma burocrática. 
por muita abstração e distanciando-se do lócus dos alunos. Esse fator, pode ter sido influenciado pela restrição educacional e formação que os próprios educadores tiverem, como é sinalizado por Estermann; Tavares; Gomes (2017, p. 26) ao se referir que "os educadores são formados para reproduzir fielmente a epistemologia dominante, numa matriz institucional e curricular dada e herdada da época colonial, com o desejo de "produzir" cidadãos que respondam ao projeto nacional dominante, ele próprio submetido ao projeto internacional dominante."

Esta corrente de educadores, tem multiplicado recorrentemente em espaços escolares um pensamento que subalterniza e primitiviza pensamentos outros, que não se fundamentam dentro da estrutura do pensamento hipoteticamente hegemônico moderno colonial eurocêntrico/ocidental, o que de certo modo, contribui para invisibilização de saberes diversos, que vivem e podem ser explorados em outras práticas culturais não eurocêntricas/ocidentais.

Entretanto, a escola sendo um espaço formal de educação, "uma instituição que tem alunos de uma diversidade de culturas e etnias" (DIAS E† Al., 2012, p.1), pode ser considerado um ambiente conflitante em que refletem os dramas existentes e vividos fora do habitat escolar, marcados por relações humanas desiguais. Esse mesmo espaço, pode criar mecanismos para formação de relações humanas democráticas, pautada no respeito às diversidades, possibilitando o rompimento da hegemonização do pensamento moderno colonial e eurocêntrico/ocidental, ao permitir que diferentes saberes circulem em espaços escolares e participem do processo de produção do conhecimento cientifico, sem a pretensão de subalternização de quaisquer outros saberes.

É neste sentido, que diferentes correntes de pensamento (decolonial, Etnociência, etnomatemática, etc.), têm se colocado como propostas que discutem ações que visam a desnaturalização do pensamento moderno eurocêntrico/ocidental, enquanto uma posição que se tem considerada hegemônica e, modelo único e universal de produção de conhecimentos. $\mathrm{Na}$ educação, esta discussão tem sido levantada em várias perspectivas que possibilitem desnaturalizar atitudes que fomentam o racismo estrutural na educação, "uma forma sistemática de discriminação que tem a raça como 


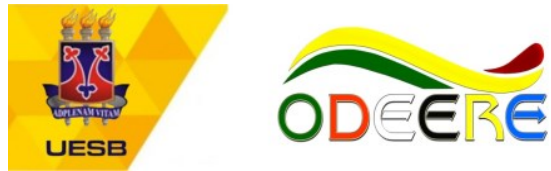

fundamento, e que se manifesta por meio de práticas conscientes e inconscientes, e que culminam em desvantagens ou privilégios para indivíduos, a depender do grupo social ao qual pertençam" (ALMEIDA, 2019, p. 22). Especificamente no campo da matemática, ao se considerar a ciência do raciocínio logico e da abstração, essa discriminação tem sido bastante acentuada, ao se negar explicita ou implicitamente que a matemática pode ser fundamentada a partir de outros saberes, que não se fecham dentro do pensamento moderno colonial eurocêntrico/ocidental, sobretudo da cultura negra africana, afro-brasileiras e indígenas, adjetivando-se esses saberes de primitivos.

Desde então, Leis e currículos de vários países têm apontado para uma educação que respeite e valorize os contextos locais, a cultura e história dos povos africanos, afrodescendentes e indígenas, que sobejamente foram silenciadas pela cultura branca e europeia/ocidental. No brasil por exemplo, com a finalidade de promover ações capazes de romper com o quadro da exclusão e invisibilidade dos fatos históricos que justificam as desigualdades sociais, foram realizadas alterações na Lei de Diretrizes e Base da Educação (LDB) em 2003 e 2008, com a pretensão de tornar obrigatório o ensino de história e cultura africana e afrobrasileira pela Lei 10.639/03, que fora alterada em 2008 pela 11.645 e, que acrescenta a obrigatoriedade do ensino de história e cultura indígena. A partir dessas leis, diversos investigadores tem se debruçado para o resgate dos valores renegados pela colonização, trazendo importantes contribuições para a educação, por exemplo, na educação matemática através da educação matemática critica, etnomatemática, etc.

Moçambique, um país que experimentou a desvalorização e negação de sua cultura, especificamente no meio escolar, pelos efeitos e marcas da colonização, também adotou importantes decisões que visassem o resgate de práticas culturais locais e integradas no ensino. Como exemplo disso, foi a promulgação da resolução n 12/97 que "aprova a Política Cultural e Estratégia de sua Implementação e, estabelece em seus objetivos específicos alínea c) a promoção a integração dos valores socioculturais nos currículos do ensino" (MOÇAMBIQUE, 1997, p. 6). Todavia, embora tenha sido promulgada essa 
resolução, ainda ouve constatações de que ela não era na integra implementada, como é explicitado em INDE/MINED (2008, p.17) ao sinalizar que "o currículo do Ensino Primário anterior a de 2006, não abria, de uma forma explícita, a possibilidade de integração do currículo local, o que fazia com que os conteúdos temáticos fossem abordados de modo uniforme e homogéneo em todo o País", o que ocasionava o não alcance dos objetivos na implementação do Sistema Nacional de Educação (SNE).

Como resposta a essa inquietação e, na pretensão do resgate dos valores culturais em meio escolar, é introduzida no Plano Curricular do Ensino Básico (PCEB) e do Ensino Secundário Geral (PCESG) a partir de 2006, uma perspetiva inovada do currículo que privilegia a "Integração de Conteúdos de Interesse Local". Assim, formalmente já estavam construídos os instrumentos teóricos que possibilitassem a flexibilização e fertilização dos currículos para integração de práticas culturasi no ensino e em diversas disciplinas. Este elemento é apontado em um dos pontos do PCEDG, nos seguintes termos:

[...] considerando o carácter flexível do currículo, a sua implementação deverá considerar aspetos de interesse local de maneira a responder às necessidades das comunidades, sendo as estratégias de abordagem desses conteúdos feitas através da valorização de experiências locais no processo de ensino aprendizagem, articulando os conteúdos propostos nos programas de ensino com a realidade local [...], (INDE/MINED, 2007, p. 31).

Por meio destas leis e resoluções, os currículos, tanto Brasileiro quanto Moçambicano, começam encontrar abertura que permitem ressignificar o ensino a partir da história e cultura de povos subjugados e primitivizados, podendo assim, se contribuir para a valorização das práticas locais ou socioculturais, com vista a uma educação que não se prese apenas pelas políticas de ensino enraizadas nas epistemologias eurocêntricas/ocidentais dominantes, de que são desenhados e inspirados muitos programas curriculares, podendo assim, conforme Estermann; Tavares; Gomes (2017, p. 17) "conferir dignidade ontológica aos povos originários e dignidade epistemológica aos seus saberes que contribuirá sobremaneira para a construção de uma nova geopolítica do conhecimento." 
Na educação Matemática, as discussões sobre as possibilidades de aproximação e relações existentes entre as práticas socioculturais e a matemática, tem sido discutida e aprofundada bastante no seio dos pesquisadores do programa de estudos e pesquisa em Etnomatemática. Moçambique em particular, o foco sobre as investigações etnomatemáticas é iniciado na década 70 por Paulus Gerdes, mesma altura em que o celebre e memorável pai da Etnomatemática, Ubiratan D'Ambrósio se desembocava para promoção de práticas de ensino enraizadas nas Ticas das Matemáticas, no Brasil e no Mundo.

Embora o trabalho de D'Ambrósio, Gerdes e outros pesquisadores da etnomatemática tivesse e tem sido brilhante, muito tem sido a resistência e os ataques a essa perspectiva pela comunidade de Educadores puramente matemáticos, que ainda sobrevivem no ambiente imbuído no pensamento moderno colonial, eurocêntrico/ocidental de produção do pensamento matemático. Todavia, a Etnomatemática tem avançado bastante para ressignificar a postura desses educadores, ao propor discussões que possibilitem desnaturalizar o racismo acadêmico, relativos aos saberes que se julgam ser primitivos ao não se inserirem na Perspetiva do pensamento moderno eurocêntrico colonial.

É assim que neste artigo, procuramos também trazer uma abordagem teórica, inserida na didática da matemática, que apoie a Etnomatemática neste debate da desnaturalização de práticas que discriminam saberes não eurocêntricos/ocidentais, através de uma posição que julgamos promover ações de decolonização epistemológica. Neste contexto, o nosso propósito é problematizar a partir dos elementos teóricos da Teoria Antropológica do Didático (TAD), uma teoria que atua a nível epistemológico e institucional, uma perspetiva que permite discutir a ação decolonial a nível da epistemologia de saberes Matemáticos e seu ensino, pensando que estaremos a contribuir para uma decolonização didática.

Para que a discussão não se torne demasiadamente teórica, apresentamos uma proposta didática, utilizando o jogo moçambicano Mbetete, para introdução de conceitos básicos de probabilidade, como uma possibilidade de desnaturalizar 
as práticas rotineiras de como tem sido na lecionação dos conteúdos sobre probabilidade. Esta proposta, enquadra-se na $12^{a}$ classe do SNE em Moçambique e no currículo Brasileiro, do $3^{\circ}$ ao $9^{\circ}$ ano de escolaridade do ensino fundamental.

\section{Elementos que caracterizam a (de)colonialidade didática}

A história da humanada nos ensina que o mundo sempre se constituiu na diversidade. De acordo com Piva (2017, p. 4700), "a diversidade se particulariza em todos os espaços e de acordo com o seu período de emergência", apontando entre várias formas de representação, a diversidade de Gênero, sexual, raça, etnia, linguística, geográfica. Pode se então notar que, em cada ponto geográfico do mundo a diversidade está lá, se manifestando, entre os seres humanos, no seu modus de vida, suas ideologias, políticas e visão de mundo.

É comum que grupos de indivíduos compartilhem determinados hábitos e costumes, sujeitos a alteração por determinadas influencias, a partir do qual, se pode caracterizar sua civilização. A humanidade registrou diversas civilizações entre os seis continentes no mundo, que isoladamente desenvolveram sua visão do mundo e contribuíram para o avanço da ciência e tecnologia no mundo, a partir dos saberes diversos que os constituíam.

Civilizações antigas como Egípcias, Persas, Mayas, etc. se constituíram importantes no desenvolvimento da Ciência e tecnologia a partir de suas práticas locais, utilizadas para resolver problemas pontuais, por exemplo, no Egito, o problema da demarcação e divisão de espaços para a prática da agricultura nas margens do rio Nilo, as técnicas de mumificação para conversação de corpos humanos e de outros animais, etc. Portanto, civilizações diversas, constituídas antes da colonização, em reinos, povoados, aldeias, etc., operavam sub uma visão própria e diferenciada, e a história demostra que diferentes povos participaram na construção do que hoje chamamos de ciência moderna, como rebate D'Ambrosio (201 1, p.28 citado por Silva, G., 2018, p.59) ao afirmar que "todas essas civilizações contribuíram para o que hoje identificamos como Civilização Moderna, que começa a se moldar a partir do século XV, na chamada Era das Navegações". 
A África e o povo Africano em particular, exerceu inúmeras contribuições e influencias sobre o desenvolvimento da ciência e tecnologia no mundo. Por exemplo, Asante (2015), Boyer (1974), Cunha (sd), Eves (2011), Roque (2012) elucidam que, para além das contribuições e influências africanas no desenvolvimento de diversas áreas como medicina (a prática de mumificação, odontologia, dos métodos contraceptivos, etc.), já conhecidos pelos egípcios, da astronomia Dogon praticada na região do Mali, da arquitetura africana representada pelas pirâmides Egípcias, das muralhas do grande Zimbabwe, etc., que ilustravam capacidade arquitetônica africana de excelência, da peonagem na sofisticada prática de navegação egípcia, no desenvolvimento da matemática, física, etc., também, contribuiu para/na formação de grandes astros da ciência como Apolônio, Arquimedes, Aristóteles, Diofanto, Euclides, Platão, Pitágoras, Ptolomeu, Tales de Mileto, etc.

Com o advento da colonização, um processo pelo qual "pessoas indo de uma região para outra com objetivo de habitar e/ou explorar" (SOUZA, 2008 citado por ZALAMENA, 2018a, p.4), com especificidade, para a invasão Europeia a Américas, Asia e África, diferentes padrões de poderes que desembocaram na "discriminação social e posteriormente codificadas como raciais, étnicas, antropológicas ou nacionais, de acordo com os momentos, os agentes e as populações envolvidas" (QUIJANO, 1992, p. 12), foram instauradas nas colônias. Este processo, que visou a ocupação de terras alheias e a eliminação e/ou escravização, pilhagem de recursos e conhecimentos de seus povos, foi acompanhado com a relegação ou destruição de culturas, práticas e princípios de con(sobre)vivência de distintas civilizações, tidas como primitivas, forçando-as a enveredar por práticas, princípios políticos-epistêmicos de cultura brancaeuropeia, tidos ante então, como modelo único e universal de civilização no mundo.

Reconhecendo que a intensidade da destruição das culturas foi diferente entre os continentes e ou países dominados, em África, como sustenta Quijano (1992, p.13), "a destruição cultural foi sem dúvida muito mais intensa do que na Ásia, mas, menos do que na América", entretanto, muitas práticas socioculturais 
conseguiram sobreviver a colonização, pelo menos, parcialmente, porém, continuamente descaracterizadas, "aos thes serem retirados a legitimidade e reconhecimento na ordem cultural mundial dominada pelas normas europeias" (QUIJANO, 1992, p.13). Embora estas práticas socioculturais tenham sobrevivido a exacerbada colonização, o processo em si deixou marcas severas, que constituem ainda hoje legados que colocam o corpo e a sabedoria branca-europeia acima de tudo e todos, enraizadas em muitos domínios "socias, culturais, da economia, da política, etc., que encontram eco no desenvolvimento dos países ainda nos dias atuais" (ZALAMENA, 2018a, 2018b).

Estes legados, que tem a principal cara $\circ$ racismo 4 estrutural, ainda ditam "processos de exclusão social e política, articulados historicamente em um modelo de desenvolvimento predatório que instituiu uma divisão internacional do trabalho, a partir da subjugação de outros povos e culturas não europeias" (BRAGATO, CASTILHO, 2014, p. 15). Portanto, embora estes países tenham sido descolonizados e se tornado independentes, as heranças do colono foram suficientemente fortes, de tal modo que a descolonização se constituiu apenas do desmembramento político-administrativo, tornando os países livres e sub governação própria, porém, perpetuando as práticas e políticas-epistêmicas do colono europeu, subestimando outras práticas e sabedorias, constituindo-se assim uma "colonização disfarçada da mente" (ESTERMANN; TAVARES; GOMES, 2017, p. 19), como reforça Quijano,

embora o colonialismo político tenha sido eliminado, a relação entre a cultura europeia, também chamada "ocidental", e as outras, continua a ser uma relação de domínio colonial. Não é apenas uma subordinação das outras culturas à cultura europeia, numa relação externa. É uma colonização das outras culturas, embora sem dúvida com intensidade e profundidade diferentes, dependendo do caso. Consiste, antes de mais, numa colonização do imaginário dos dominados. Ou seja, actua na interioridade deste imaginário. (QUIJANO, 1992, p. 12).

Estes efeitos da colonização, que tem sido designado teoricamente por colonialidade (BERNARDINO-COSTA; GROSFOGUEL, 2016), configura segundo

\footnotetext{
4 De acordo com Almeida (2019, p. 22), racismo é uma forma sistemática de discriminação que tem a raça como fundamento, e que se manifesta por meio de práticas conscientes e inconscientes, e que culminam em desvantagens ou privilégios para indivíduos, a depender do grupo social ao qual pertençam.
} 
Giraldo (2021, p.2) "um padrão de poder que emerge do colonialismo5 territorial moderno, mas que sobrevive a esse e não se limita à dominação formal de uma nação sobre outra, operando nas formas como o trabalho, o conhecimento e as relações intersubjetivas que se manifestam e se articulam entre si". Portanto, tratase de um processo que o ocidente se apropriou, criando uma imagem que centraliza as sabedorias brancas e eurocêntricas como únicas formas de conceber o desenvolvimento do mundo, neutralizando outras sabedorias.

Trata-se então, dos efeitos da colonização, que tem sido (re)produzido não só pela cultura branca eurocêntrica, mas também por aqueles que foram educados sob pensamento hegemônico moderno colonial/eurocêntrico, que naturalizam estas práticas colônias. É assim, que muitas políticas-teóricasepistêmicas eurocêntricas ficaram enraizadas nas suas colônias, podendo ser (re)alimentadas a partir de sistemas educacionais já viciados, entre outros setores, numa clara evidencia de absorção, invisibilização de outras práticas socioculturais, políticas-epistêmicas que não circulam somente nas artérias da hegemonia do pensamento ocidental e/ou moderno colonial, "relegadas a um lugar do atraso e do primitivismo" (GIRALDO, 2021, p.2).

De acordo com Santos (2018, p.4), estas práticas discriminatórias tem se alicerçado "na racialização e as intrínsecas formas racializadas das relações de produção; no eurocentrismo, como forma de produção e controle das subjetividades, das existências; na hegemonia do Estado-nação que, como processo intrínseco, após o colonialismo, é construído como periferia". Portanto, como secunda Bernardino-Costa; Grosfoguel (2016, p. 18), "associado a este sistema de classificações dos povos do mundo, ligado a este esquema de racialização, houve também um processo de dissimulação, esquecimento e silenciamento de outras formas de conhecimento que dinamizavam outros povos e sociedades". Desta forma, eles fortalecem suas relações de poder ao naturalizar suas vozes, suas políticas e princípios epistemológicos, logrando-se como formas

5 Para Quijano (1992, p. 11), o colonialismo foi um padrão operacional da colonização (um sistema de dominação política formal de algumas sociedades sobre outras), que estabeleceu uma relação de dominação direta, política, social e cultural dos europeus sobre os povos conquistados de todos os continentes. 
únicas e absolutas de ver o mundo, primitivizando outras culturas, sabedorias e epistemologias que não se fundamentam apenas dentro do escopo do pensamento moderno eurocêntrico/ocidental, como sustenta Giraldo ao refere-se que,

\begin{abstract}
Essas epistemologias dominantes ou hegemônicas apresentam-se como possibilidades únicas, ou seja, as sabedorias dominantes tem uma característica delas para preservar o seu próprio projeto de poder, que é apresentarem-se em si próprias como a única possibilidade ou a maneira natural de fazer as coisas, a partir de uma noção linear e universal de progresso. Essa noção de progresso, tem como referência a cultura e sabedoria branca e eurocêntrica. Assim, tudo que se alinha a essa noção de progresso é alçado ao lugar de desenvolvimento e tudo que não está alinhado a essa noção, referenciada numa cultura branca e eurocêntrica é relegado ao lugar de primitivismo e de atraso. Portanto, essa noção linear de progresso ela naturaliza certas relações de dominação na nossa sociedade e é usado para justificar determinado esquema de relação de poder na sociedade, para naturalizar. (GIRALDO, 2020a)
\end{abstract}

Portanto, essa visão do mundo, que procura a todo custo invisibilizar e subalternizar pensamentos outros, colocando no centro da atenção o pensamento hegemônico de cultura branca e eurocêntrica, como forma única de justificar o desenvolvimento e avanço da ciência e outras práticas no mundo, ou nos países outrora colonizados pelos europeus, vem sendo amplamente insurgidas pelo movimento de pesquisadores do pensamento decolonial, que, "ao questionar o projeto moderno, eurocêntrico e ocidental de ciência, tem, se colocado como lente capaz de denunciar e questionar de modo complexo a sofisticação discriminatória das bases epistêmicas na ciência" (SANTOS, 2018, p.2), as outras formas de construção do pensamento cientifico.

Entre os espaços de reprodução desse poder hegemônico, a educação tem sido ainda hoje uma área onde essas relações de puder tem sido fomentada, embora, a existência de um movimento grade dentro desta mesma área que tem estado a resistir a essas práticas discriminatórias do saber, através da raça. Observamos ainda hoje, que currículos, na sua maioria são compilados sub uma visão que facilita a reprodução do poder hegemônico, que descaracterizam outras sabedorias não eurocêntricas e distanciam o aluno da sua realidade, incutindo-lhe continuamente o pensamento de que suas práticas são não 
cientificas e sem legitimidade para participarem do processo de produção do conhecimento cientifico. Como é de salutar, estas práticas procuram de todas as formas, minimizar e invisibilizar outros saberes, produzidos ali, onde se dá as relações de ensino, mas não são levados em conta, o que coloca muita das vezes em questionamento a razão de ser destes conteúdos de ensino a aqueles para quem se deseja ensinar.

Esta forma de atuação tem conduzido muito dos educadores a linearização e universalização do ensino, que naturaliza praxeologiaśb didáticas, ao apresentarem de forma inquestionável e não problematizada as epistemologias eurocêntricas, como modo único para o ensino e aprendizagem de ciências diversas no ensino. O ensino da Matemática, em particular, por muito tempo foi e tem sido marcado por essa linearização das práticas de ensino, que tendem a minimizar ou ocultar a existência de práticas matemáticas fora do contexto ocidental, como elucida Gerdes, ao sinalizar que,

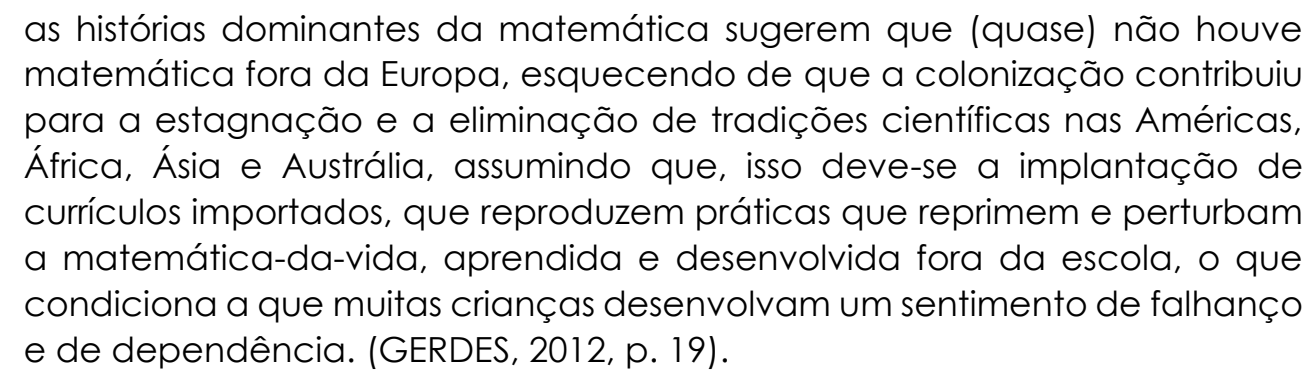

Essa linearização universalista no ensino da Matemática, que é marcada frequentemente pela reprodução e/ou inventario inquestionável de praxeologias matemáticas de "referências a cultura e sabedoria branca e eurocêntrica" (GIRALDO, 2020a), caraterizado por muita abstração e distanciando da realidade sociocultural a que os alunos vivem. Portanto, o distanciamento entre a matemática acadêmica e a matemática da vida cotidiana, cria desafeto aos alunos e, consequentemente, propicia o bloqueio ao processo de educação

6 Para situar o leitor, apresentamos uma ideia inicial do termo "praxeologia ou organizações praxeologias", na lógica que utilizaremos e interpretaremos neste trabalho, considerando que, ao longo da escrita o termo fique mais familiar e compreensível. Portanto, para Chevallard (2018, p.34) "praxeologias designa de maneira genérica "an ability that has been acquired by training", que permitir designar, sem afetações epistemológicas-culturais, sem juízos de valor a priori ou a posteriori, toda estrutura de conhecimento possível". 


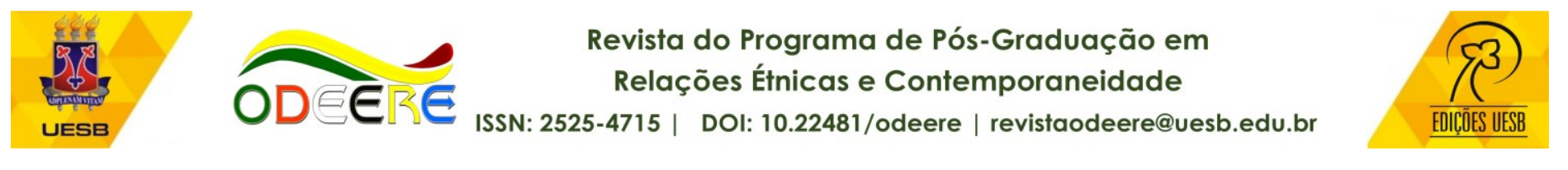

(PAPERT, 2008).

Esta posição política - epistêmica, tende a tornar-se rotineira e "monumental" no processo de ensino e aprendizagem (PEA) da matemática, levado com que se instaure uma pedagogia caraterizada pelo "paradigma escolar de inventario de saberes", em que, objetos ${ }^{7}$ matemáticos são apresentados a partir de uma "leitura invariante do universo dos saberes" (CHEVALLARD, 2018). Para além disso, essa leitura invariante é imersa quase ciclicamente em uma epistemologia e/ou sabedorias eurocêntricas/ocidentais, que descrimina outras sabedorias oriundas do lócus, aonde a escola e os alunos estão inseridos.

Portanto, estes objetos matemáticos são difundidos aos alunos sem que sejam questionados ou problematizados, de modo que possam "privilegiar a produção de sentidos e de afetos, em lugar da exposição de fatos, procedimentos e informações (GIRALDO, 2019, p. 8). Esta prática, constituem uma característica inequívoca da colonialidade no ensino da matemática, ou melhor, por estas práticas rotineiras que naturalizam a produção escolar de saberes da matemática a partir da epistemologia hegemônica eurocêntrica/ocidental como única forma de produção do saber, podemos dizer que, o ensino da matemática reproduz ou vive de reprodução da colonialidade.

É sobre esta colonialidade epistemológica do saber no ensino da matemática, que apresentamos neste texto a decolonialidade didática como uma postura que nos possibilita, primeiramente questionar como é que os objetos de saber da matemática vivem nas instituições escolares, ou melhor, que praxeologias são impostas aos objetos? porque que vivem daquele jeito? O que faz com que elas permaneçam hegemônicas? Que praxeologias existem fora do espaço escolar e que não está ali? Porque não estão? etc.

7 De acordo com Douady (1986, p. 9, tradução nossa), objeto ou objeto didático refere-se ao "objeto cultural que tem o seu lugar num edifício maior, que é o conhecimento académico num dado momento, socialmente reconhecido". Chevallard (2018) vai mais longe ao sinalizar que, ao objeto, referimo-nos a "qualquer entidade, material ou imaterial, que existe, ao menos, individualmente, ou particularizando, qualquer trabalho ou produto intencional da atividade humana, entre artefatos, noções, símbolos, etc.". Estas ideias, são sumarizadas por Almouloud (2010) ao se referir de forma mais precisa que um objeto é nada mais que um conteúdo de aprendizagem, ou seja, um conteúdo que se deseja aprender em um dado instante e em um lugar especifico. 
Segundo, partindo destes questionamentos, que nos farão compreender a natureza e a complexidade da naturalização das epistemologias hegemônicas de cultura branca, eurocêntrica/ocidental no ensino da matemática, buscamos ações didáticas que possibilitem descontruir os padrões hegemônicos de produção de saber matemático escolar, propondo alternativas que possibilitem a aprendizagem da matemática a partir de outras epistemologias que não se fundamentam apenas nas epistemologias eurocêntricas ocidentais.

A didática da matemática, entra assim neste jogo de resistência e produção de ações que visam a desnaturalização das práticas de ensino que subalternizam e primitivizam sabedorias outras, questionando a razão de ser do objeto em seu ambiente conceitual, e propondo mecanismos de analisar outras praxeologias não eurocêntricas em ambientes escolares. Por ser um campo de discussão complexo, neste artigo levamos em consideração a didática da matemática no contexto da Teoria Antropológica do Didático (TAD), uma teoria que "situa a atividade matemática, no conjunto das atividades humanas e instituições sociais" (CHEVALLARD, 1999, p. 223; ALMOULOUD, 2010). O seu cerne é o estudo do objeto a nível epistemológico e institucional e tem como a principal unidade de análise das atividades a "praxeologia".

A TAD propõe o estudo do saber Matemático, no complexo das interações e relações entre o homem e o saber em seu ambiente conceitual, considerando ainda o lócus para o qual se dá o sistema de relações professor-aluno-objeto. Este caráter permiti então, que o didata consiga estudar e explicar a estrutura lógica dos objetos de saber matemático, a analise praxeológica, desde a sua condição de existência em sua realidade institucional à difusão e apropriação pelo aluno, o que vamos a designar de abordagem ecológica do saber.

Assim, a partir dos elementos da TAD, especificamente abordagem ecológica do objeto de saber, se propõe questionar o objeto no seu habitat, do ponto de vista epistemológico institucional, o que é que existe, o que é que não existe, porque não existe, o que deveria existir, que possibilidades poderia ter para existir, etc. Por outro lado, com a analise praxeológica, que é a principal unidade de analise na TAD, pode-se desencadear propostas que visem analisar a estrutura 
lógica de saberes não eurocentrados, que vivem ali, onde se dá as relações de ensino, mas que não são considerados no meio escolar, por causa de descriminação epistemológica.

\section{Abordagem ecológica: uma metodologia didática que possibilita questionar e mostrar a existência de saberes e práticas que se perpetuam no ensino da matemática}

Ao colocar o objeto no seu interesse de estudo, a TAD empresta o termo "ecologia" para situar a natureza do objeto diante de sua condição de existência, ou melhor, em seu meio de sobrevivência. O termo tem a sua gênese na Biologia, "proposta pela primeira vez pelo biólogo alemão Ernest Haeckel, em 1869, em sua obra Generelle Morphologie der Organismen" (ODUM, 1988; CASSINI, 2005, P. 2). A ecologia, refere-se em geral a ciência do habitat, a ciência que objetiva o estudo das relações dos organismos ou grupos de organismos com o seu ambiente, ou melhor, que trata do estudo das condições de existência dos seres vivos e as interações, de qualquer natureza, existentes entre esses seres vivos e seu meio. (ODUM, 1988, p. 4; CASSINI, 2005, p. 2).

No campo da Didática da Matemática, ela aparece como uma metodologia que permite descrever e caracterizar o objeto em seu meio de sobrevivência, apontando as condições e restrições para o qual deve ou não deve sobreviver em determinado ambiente. Trata-se de apresentar e caracterizar a razão de ser do objeto, isto é, caracterizar onde ele vive, como vive, porque vive, em que circunstancias vive ou não deveria viver neste ambiente, etc.

Levando em conta o fenômeno de transposição didática, um processo pelo qual objetos de saber sofrem diversas transformações, quando sujeitos a migração de um ambiente para outro, do qual devam se inserir, a "a ecologia do didático ou analise ecológica", permite ao ditada $\xi$ que se questione continuamente sobre: "de onde vêm estes novos objetos ensinados? como é que chegaram lá? que interrelações, com que outros objetos, estabelecem lá? E, também, acima de tudo: por que chegaram lá?" (CHEVALLARD, 1994, p. 5).

Para Castela (2019, p. 5), "a ecologia do didático é o ramo da didática que 
estuda as relações e interações entre fenômenos didática e os ambientes em que são desenvolvidos". A autora enfatiza ainda que a metodologia que conduz a analise ecológica, permite que o didata ou investigador "se livre do que designa de ilusão de transparência, ou seja, a problematização a realidade didática do objeto, no seu passado, presente e das leis que regem à ecologia do objeto" (CASTELA, 2019, p. 7). Esta problematização, permite caracterizar a natureza ecológica do objeto, podendo então ser requerida ao responder determinados questionamentos, como os apontados por Chevallard (1994), ou como os apresentados refinadamente por Castela:

No presente: o que existe e por quê? e também, o que não existe e por quê? No passado: o que desapareceu, se alguma coisa, e por quê? Em outro lugar: o que existe e não existe aqui? Porque? Na busca por leis que regem a ecologia da didática: em que condições esse fenômeno pode ocorrer? Que restrições evitam que tal fenômeno ocorra? (CASTELA, 2019, P. 7).

Assim, a partir destes questionamentos e de acordo com Farras (2009), a Didática da Matemática por meio da TAD, procura questionar e esclarecer quais as condições que favorecem que certas atividades possam ser ensinadas ou aprendidas melhor, que certas atividades matemáticas e didáticas possam desenvolver-se num determinado ambiente institucional e quais são as restrições que dificultam a realização dessas atividades. Portanto, a analise ecológica se torna assim indispensável em qualquer estudo ou investigação em didática, pois, permite clarificar em que condições, determinado objeto sobrevive em um ambiente, que funções vai ou não vai poder desempenhar nesse ambiente. Como é de salutar, esta metodologia leva em consideração dois conceitos importantes, "O de habitat, que se refere ao lugar específico onde o objeto pode ser encontrado, isto é, o seu endereço dentro do ecossistema e ao nicho ecológico, que se refere ao papel que o objeto desempenha no ecossistema, isto é, a função do objeto no ecossistema" (CHEVALLARD, 1994, p. 5; CASSINI, 2005, p. 4; ALMOULOUD, 2015, p.15).

Ao questionarmos o que existe ou o que está posto e porque, levantamos possibilidades de desvendar, a partir da análise de documentos oficiais (programas de ensino, livros didáticos, entre outros), de relatos de professores e entidades 
externas ao sistema escolar, como a epistemologia eurocêntrica/ocidental está enraizada no processo de difusão de praxeologias matemática. A partir daqui, pode-se então compreender porque que a epistemologia dominante e dominante no ensino da matemática, como este sistema de relações pessoais ao objeto que é apresentado no sistema escolar, reproduz a colonialidade. Este esclarecimento, favorece então, que ao compreendermos como estão postas as praxeologias no ensino da matemática, possamos pensar em ações que permitam desnaturalizar estas práticas que hegemonizam as sabedorias eurocêntricas/ocidentais e subalternizam as não ocidentais, no processo de produção de saberes escolares da matemática. Estas possibilidades outras, podem ser (re)construídas ao analisarmos didaticamente "o que não existe e como poderia existir" no sistema de relações pessoais aos objetos de saber.

Portanto, a abordagem ecológica é um ponto de partida para o questionamento e análise das condições que fazem com que as epistemologias eurocêntricas/ocidentais permaneçam e vivam ciclicamente no ensino da matemática e tidas como únicas formas de produção do saber matemático escolar. Por outro lado, esta abordagem dá-nos a possibilidade de analisar as restrições pelas quais os saberes não eurocêntricos não vivem nas instituições escolares e por via disso, poder-se estudar ações que possam permear que os saberes não eurocentralizados circulem em ambientes de ensino formal e participem do processo de produção cientifica, com especificidade, para produção de saberes matemáticos.

\section{Abordagem praxeológica: uma possibilidade para integração e analise da circulação de saberes não eurocentrados ao ensino da matemática}

Em didática da matemática, a TAD ocupa um papel fundamental no estudo e análise das condições e restrições das praxeologias inerentes ao processo de ensino e aprendizagem de objetos matemáticos. Este conceito é adotado no sentido estrito da TAD, situando a Atividade Matemática como uma Atividade humana realizada e regulada por praxeologias que uma pessoa - $x$, na posição p, de uma instituição - I, implementa para manter sua relação com o objecto - o. 
Conforme Chevallard (2018b, p. 35), "a TAD define a didática como a ciência das condições e restrições da difusão social das praxeologias, em particular, define a didática da matemática como a ciência das condições e restrições da difusão social das praxeologias matemáticas".

As praxeologias são em geral inerentes a objetos de aprendizagem que vivem em determinada instituição, ou seja, para qual $o$ existe ou tem uma relação não vazia para $\mathrm{I}$, isto é, $R_{I}(o) \neq 0$, em que $\mathrm{x}$ deverá se assujeitar conforme as condições e restrições impostas por I para que possa constituir seu universo cognitivo $U C(x)$ com relação a $o$, ou melhor para que $o$ exista para $\times$ em I, uma relação que é denotada por $R_{I}(x, o)$, o que torna indispensável na TAD tratar das (inter)relações instituição - objeto - pessoa. (CHEVALLARD, 2018b).

Assim, as praxeologias ao fazerem parte do processo da modelação da Atividade humana, são caracterizadas pelo quarteto praxeológico $[T, \tau, \theta, \Theta]$, que constitui sua estrutura mínima, subdivididas em dois blocos fundamentais, a práxis, relativo ao saber-fazer, e o logos, relativo ao saber - sábio, onde:

Quadro 1: descrição dos elementos do quarteto praxeológico

\begin{tabular}{|c|c|}
\hline \multirow[t]{2}{*}{$\begin{array}{l}\text { Bloco Práxis - }[T, \tau] \\
\text { Saber - fazer }\end{array}$} & $\begin{array}{l}T \text { : Refere-se ao tipo de tarefa, que é identificável por um verbo de } \\
\text { ação (calcular ..., jogar..., lavar..., etc.) e que implica em um objeto } \\
\text { que complementa o verbo (calcular a área de um triangulo, jogar o } \\
\text { Ntxuva, ..., etc.). Assim, } T=\left\{t_{1}, t_{2}, \ldots, t_{n}\right\} \text { constituem um gênero de } \\
\text { tarefas, em que } t_{i} \in T, \text { com } i=1,2,3, \ldots \text { é uma tarefa especifica, que } \\
\text { implica um objeto. }\end{array}$ \\
\hline & $\begin{array}{l}\tau \text { : Refere-se as técnicas, ou seja, a maneira de executar/resolver uma } \\
\text { tarefa especifica. Estas, estão sujeitas as condições e restrições da } \\
\text { instituição a que a tarefa pertence. }\end{array}$ \\
\hline \multirow{2}{*}{$\begin{array}{l}\text { Bloco logos - }[\theta, \Theta] \\
\text { Saber - saber }\end{array}$} & $\begin{array}{l}\text { a: Refere-se à tecnologia da técnica, isto é, as formas como as } \\
\text { técnicas utilizadas são justificadas. Um discurso que permite tornar } \\
\text { inteligível ou ainda produzir a técnica. }\end{array}$ \\
\hline & $\begin{array}{l}\text { } \Theta \text { : Refere-se à teoria subjacente a tecnologia. Uma maneira geral de } \\
\text { justificar a gênese das técnicas aplicadas para resolução de } \\
\text { determinada tarefa. }\end{array}$ \\
\hline
\end{tabular}

Fonte: Adotado de Chevallard (2017)

Portanto, em ambiente escolar, diremos que $\mathrm{x}$ formaliza sua relação com $o$, se consegue cumprir ou implantar de forma satisfatória todas as praxeologias que Ihe fazem constituir seu $U C(x)$ com relação a $o$, sub uma instância de apoio y, neste caso, diremos ainda que $x$ conhece 0 . Em nossa perspectiva, que pretende ser uma perspectiva que analise as praxeologias não eurocêntricas, aquelas que 
vivem ao redor do ambiente escolar, mas não estão ali participando do processo de construção da ciência, consideramos que x formalizará sua relação com o por meio da (re)utilização ou implementação de praxeologias de uso em diversas praticas culturais não eurocentradas. Este fenômeno que vai nos permitir analisar saberes não eurocentrados e traze-los em ambiente escolar para que participem do processo de produção da ciência, vamos aqui designar de "circulação de saberes ou de praxeologias entre instituições".

É preciso lembrar, que a partir da noção da abordagem ecológica, a TAD permite desmistificar as praxeologias que estão postos e enraizadas nos currículos, podendo então, mostrar que elas se fundamentam ciclicamente nas epistemologias eurocêntricas, a favor da subalternização de praxeologias outras, que não se fundamentam dentro da hegemonia do pensamento moderno colonial eurocêntrico/ocidental. Ao procurar analisar como é a vivencia do objeto em seu ambiente de vida, ela consegue visualizar as lacunas e restrições que os currículos impõem em relação a integração das praxeologias oriundas de práticas culturais não eurocêntricas/ocidentais, o que permite dar uma autonomia ao didata, denunciar a ignorância que é feita as outras sabedorias não eurocêntricas em espaços escolares, salas de aulas, currículos, etc. A partir dessa denuncia, é possivel que sejam tomadas acções que desnaturalizem essa descriminação epistemológica, promovendo-se por exemplo a circulação de sabedorias não eurocêntricas em espaços escolares, para aprendizagem da matemática.

Silva e farias (2020), em um artigo que se debruçam sobre "caminhos para uma descolonização epistemológica: contribuição para a descolonização da didática da matemática", destacam também que a TAD questiona a vida do objeto e denuncia as ignorâncias institucionais, que fecham os caminhos para os reconhecimentos de outras sabedorias não eurocêntricas. Os autores salientam também que, a partir daí, se abrem possibilidades de e para reconstrução de praxeologias que vivem em outras práticas culturais e trazê-las ao meio escolar, como fundamentam: 
técnicas, tecnologias, teorias) que foram selecionados no processo de institucionalização. (SILVA; FARIAS, 2020, p.125).

Pode-se então dizer que, a TAD enquanto uma teoria da didática da matemática, que visa a análise das condições de difusão de praxeologias matemáticas, assumi um contributo importante na/para decolonização epistemológica de saberes no ensino de ciências e Matemática. Primeiramente, ao denunciar as inocências nos documentos oficiais (currículos, livros, etc.), segundo, ao possibilitar que praxeologias outras, não eurocêntricas, possam ser analisadas e deslocadas ao espaço escolar para participarem do processo de produção do conhecimento cientifico, como demonstraremos a seguir, no processo de circulação de praxeologias entre instituições.

\section{Praxeologias que circulam de instituições socioculturais não eurocentradas a instituições escolares formais}

O nosso ponto fundamental de discussão reside na relação pessoal a um objeto $R_{I}(x, o)$. Nos tópicos anteriores, discutimos como tem sido a relação pessoal a um objeto no ensino da matemática e, destacamos que é uma relação que tem sido intricadamente embutida na hegemonia do pensamento moderno colonial e eurocêntrico/ocidental. Uma relação que ignora saberes oriundos de práticas não ocidentais e, que não permitem que os objetos sejam questionados ou problematizados de modo que produzam sentidos e afetos aos alunos.

Essa relação $R_{I}(x, o)$, é comum que se dê por meio do que Chevallard(2018b) designa por "paradigma escolar do inventário dos saberes" em que as praxeologias implementadas para constituição do $U C(x)$ com relação à $o$, são meramente abstratas, mecanizadas, baseadas na reprodução fiel das praxeologias apresentadas nos livros escolares, que estão enviesadas em epistemologias ocidentalizadas, e que de certo modo não permite a autoprodução ou auto-construção do saber. Esta prática, em partes não permite que o $U C(x)$ com relação a $o$ se constitua através da descrição de situações de ensino que integrem saberes socioculturais não eurocentrados/ocidentalizados, mas também, pode impactar na questão de que a $R_{I}(x, o)$ não seja suficiente para 
que $x$ consiga visualizar a importância que as práticas socioculturais ao seu redor possuem na produção e/ou construção do conhecimento (matemático, histórico, físico, etc.) sobre $o$.

Nesta seção, em particular, apresentamos uma ampliação e ressignificação do modelo praxeológico proposto por Chevallard e, principalmente, do modelo de transposição de saberes entre instituições de investigação $I_{r}$ a instituição que utiliza $I_{p}$ proposto por Corine Castela (ver fig. 1), que ilustra, como saberes de uma instituição de investigação podem sofrer transformação e dar lugar a vários outros saberes de acordo com os interesses científicos, escolar, etc.

$$
\left[T, \tau, \theta^{r}, \Theta\right] \leftarrow I_{r} \smile\left[L^{T^{*}, \tau^{*},} \begin{array}{l}
\theta^{*} \mathrm{r}, \Theta^{*} \\
\theta \mathrm{p} \Theta^{\mathrm{p}}
\end{array}\right] \leftarrow I_{p}{ }^{\mathrm{I}_{\mathrm{p}}}
$$

Figura 1. o modelo de transposição de $\boldsymbol{I}_{\boldsymbol{r}}$ a $\boldsymbol{I}_{\boldsymbol{p}}$. Fonte: Castela (2017, p. 422)

A partir deste modelo, fizemos um recorte a nível inferior, de $I_{r}$ para $I_{p}$, para explicar como a didática da Matemática, por meio da TAD, pode promover ações que permitam levantar e analisar epistemologias oriundas de saberes não eurocentrados e, desloca-las para o espaço escolar de modo que possam participar do processo de construção do conhecimento cientifico, em particular do conhecimento matemático escolar. Este processo, que chamaremos em diante de circulação de praxeologias entre instituições.

Reconhecendo que toda instituição (cultura, científica, social, etc.) possui um potencial epistemológico, se demonstra pelo processo de transposição de saberes, que praxeologias oriundas de instituições socioculturais não eurocentradas $\overline{S C}$ podem ser (re)utilização, (re)construídas para dar lugar a um saber a ser aprendido pelo aluno. Para mostrar o funcionamento desse processo de transposição, vamos denotar $I_{\overline{s c}}$ por instituição de produção de saberes socioculturais não eurocentrados e $I_{e}$ a instituição de ensino (matemática, física, história, etc.). E então, como é que esse processo ocorre e pode ser analisado?

Primeiramente, este processo só ocorre quando $x$ possui uma relação não vazia com a pratica ou o objeto sociocultural $O_{\overline{S c}}$, isto é, $R_{I_{\overline{S C}}}\left(x, O_{\overline{S C}}\right) \neq \emptyset$, ou melhor, $x$ conhece e tem uma relação de pertencimento ao/do lugar e do objeto 
sociocultural não eurocentralizado, pois, conhece suas regras, sua história, etc. Para o aluno $x_{a}$, essa relação pode ser construída na medida que o professor $x_{p}$ lhe propõe o contato com $O_{\overline{s c}}$ por meio de atividades de estudo (AE) diversas e criativas, que the permitem implementar e/ou emergir praxeologias $P_{\overline{s c}}$ que 0 façam constituir seu universo cognitivo $U\left(x_{a}\right)$ em relação a $O_{\overline{s c}}$. Da relação $R_{I_{\overline{I c}}}\left(x_{a}, O_{\overline{s c}}\right)$ e sub instância de ajuda $x_{p}$ na implantação das $\mathrm{AE}$, praxeologias $P_{\overline{s c}}$ são (re)construídas para dar lugar ou acesso ao saber disciplinar (matemática, história, física, etc.), de onde $x_{a}$ constituirá uma relação não vazia com o objeto de ensino $O_{e}$, que tem seu habitat em uma instituição de ensino $I_{e}$, isto é, $R_{I_{e}}\left(x_{a}, O_{e}\right)$. Este processo, designamos neste artigo de processo de transposição de praxeologias entre instituições socioculturais não eurocentradas a de ensino $I_{\overline{s c}} \hookrightarrow$ $I_{e}$, um processo que é ilustrado na fig. 2.

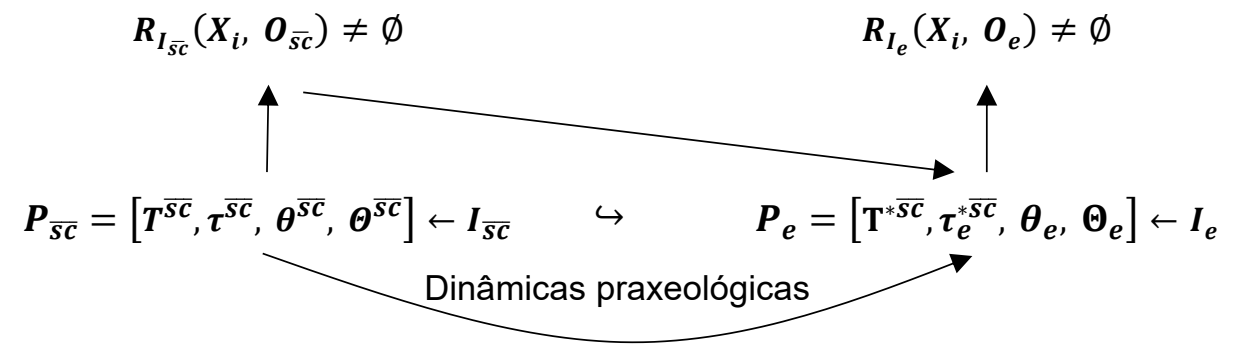

Figura 2. Processo de transposição de praxeologias entre $\boldsymbol{I}_{\overline{\boldsymbol{s c}}}$ e $\boldsymbol{I}_{\boldsymbol{e}}$. Fonte: Autores (2020), adoptado de Chevallard e Castela

O esquema ou modelo adotado complementa segundo Chevallard (2018b) o processo de transposição didática, a que se designa transposição entre instituições, neste caso concreto, a transposição de saberes ou de praxeologias de uma instituição sociocultural não eurocentrada/ocidentalizada $I_{\overline{s c}}$ para uma instituição de ensino $I_{e}$ da matemática, história, física, etc. A função social de $I_{\overline{s c}}$ é produzir e implementar praxeologias $P_{\overline{s c}}$ que permitam $x$ ser um bom sujeito de $I_{\overline{s c}}$ ou simplesmente, que permitam $x$ (re)construir seu universo cognitivo com relação ao objeto ou contexto sociocultural $O_{\overline{s c}}$, denotado aqui por $R_{I_{\overline{S c}}}\left(x_{a}, o_{\overline{s c}}\right)$, para que depois, por intermédio da instância $x_{p}$ de ajuda, possa (re)utilizar $P_{\overline{s c}}$ para (re)construir praxeologias de ensino $P_{e}$ que lhe permitam manter sua relação com objeto de ensino $O_{e}$ da matemática, história, física, etc. em $I_{e}$, ou ainda, que $x_{a}$ seja 
um bom sujeito de $I_{e}$, a que denotamos por $R_{I_{e}}\left(x_{a}, o_{e}\right)$.

Assim, a didática da matemática por meio dos elementos teóricos da TAD, possibilitará que saberes que vivem em $I_{\overline{S c}}$, que tem sido subjugado e descriminado pela hegemonia do pensamento moderno colonial, em meio a produção de conhecimentos escolares de diversas disciplinas, possam ser integrados em meio escolar e participem ativamente no processo de construção do conhecimento cientifico. Portanto, a TAD amplia assim a sua dimensão antropológica, participando teoricamente de um processo de desconstrução, de insurgência ao paradigma tradicional de ensino, primeiramente por meio da abordagem ecológica, ao denunciar práticas discriminatórias de saberes não eurocêntricos, segundo, ao propiciar por meio do processo de transposição de praxeologia entre instituições, resgatar e deslocar praxeologias socioculturais renegadas pela ciência ocidental as instituições escolares, para trabalhar conceitos, propriedades, historias, etc. a partir do lócus, de modo que o ensino produza sentidos e afeto ao aluno.

\section{O Jogo Mbetete: uma possibilidade de construção de um modelo didático de referência para o ensino de conceitos básicos sobre probabilidade}

Mbetete é um jogo tradicional praticado no território Moçambicano. Faz parte de um conjunto de outras práticas culturais locais orais, que não estão documentadas e que é transmitida de geração em geração. O nosso contato com o jogo foi no distrito de Changara, localidade de N'temangau, a partir do especialista e treinador de jogos tradicionais locais para o festival nacional dos jogos tradicionais, o senhor Pita Jhon Tembo (em anexo o termo de consentimento livre e esclarecido), que nos acolheu e prontificou-se em passar as informações relevantes sobre vários jogos tradicionais, entre eles, o Mbetete.

Em uma partida única, gravada por meio de uma filmagem, realizamos vários questionamentos ao especialista na medida em que o jogo decorria. Com estes questionamentos, visamos compreender melhor o espirito do jogo, desde a sua gênese a prática. Alguns elementos que apareceram ao longo da jogada, nos deram impressão de que o Mbetete seria um potencial jogo para trabalhar em sala de aulas os conceitos básicos e introdutórios sobre probabilidade, o que deu 
origem a ideia da organização didática que apresentaremos a seguir.

Sobre a sua gênese, o especialista não deu muitos detalhes, embora estivessem presentes alguns anciões da localidade, também eles não souberam dizer muita coisa sobre a gênese do jogo. Entretanto, foi-nos passado que o nome "Mbetete" significa na língua local "estar aberto, ou simplesmente, aberto", que é o que simboliza e caracteriza o jogo, isto é, à medida que as peças do jogo são atiradas, ao caírem, elas ficam aberta, como é ilustrado nas fig. 3 e 4. Relativamente peças do jogo, são feitas de caniço, uma planta que cresce nas margens de rios, lagoas, etc.

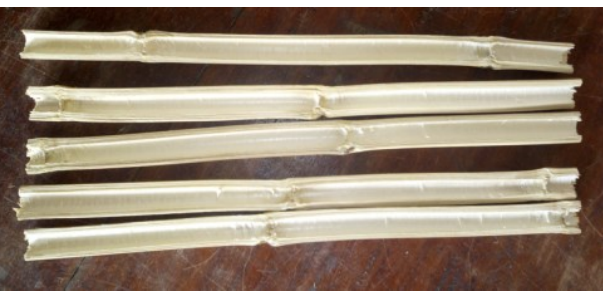

Figura 3. peças de caniço abertas. Fonte: Autores (2020)

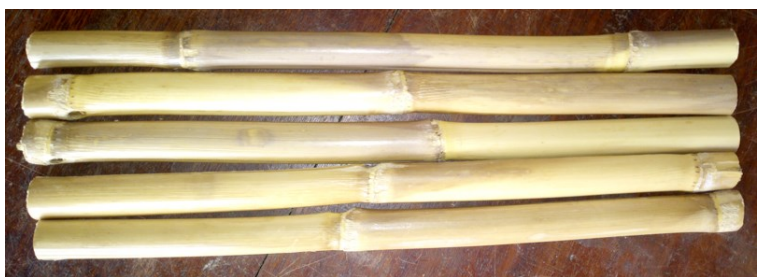

Figura 4. peças de caniço fechadas Fonte: Autores (2020)

Em Moçambique, o caniço é uma matéria prima bastante utilizada para o fabrico de esteiras caseies (fig. 5), que são utilizadas para que as pessoas se sentem. O caniço é ainda utilizado para construção e cobertura de casas, restaurantes (fig. 6).

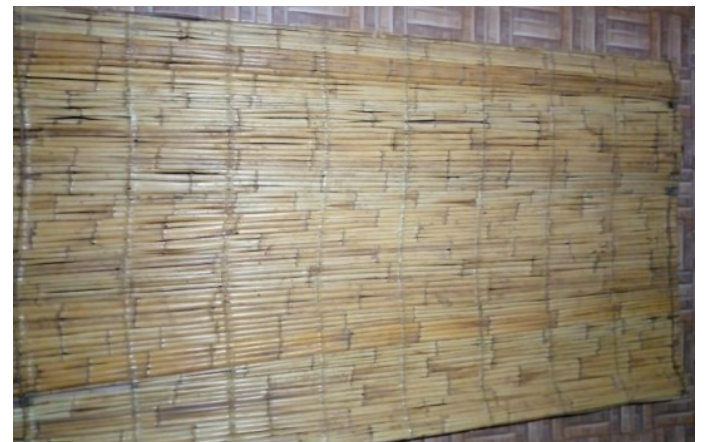

Figura 5. Esteira feita de caniço. Fonte: Autores (2021).

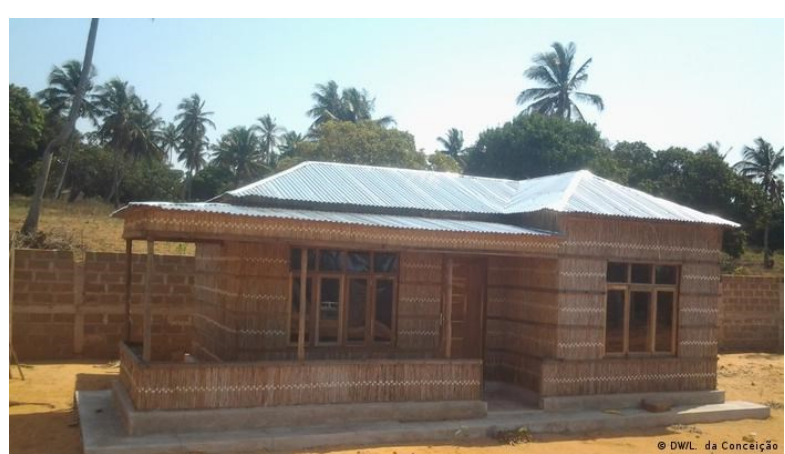

Figura 6: Casa feita de paredes de caniço. Fonte: Conceição (2019)

Relativamente a prática do jogo, foi-nos relatado primeiramente que não existe um número especifico de jogadores para disputa, porém, no mínimo deve 
haver dois jogadores. Cada jogador deve ter inicialmente 10 pedrinhas as quais, cada vez que tiver feito uma jogada certa, deverá se livrar das pedrinhas, entregando-as ao adversário mais próximo. O número de pedrinhas a serem liberadas para o adversário, depende da posição em que as peças de caniço se dispõem no chão após o lançamento.

Trata-se de um jogo de azar, cujo o experimento é tipicamente aleatório, produzindo resultados imprevisíveis. Ganha o jogo quem tiver se livrado primeiro de todas as pedrinhas. Por exemplo, se no lançamento obtém-se todas as peças fechadas, o jogador entrega ao adversário 10 pedrinhas e imediatamente é tido como vencedor da partida. Se obtém todas as peças abertas, ele entrega 5 pedrinhas ao adversário. No quadro 4 são apresentadas todas as possibilidades de um jogador se livrar das pedrinhas, cada vez que efetua uma jogada. É importante lembrar que, a jogada passa ao jogador seguinte quando o jogador atual não consegue obter um resultado que the permita livrar-se das pedrinhas.

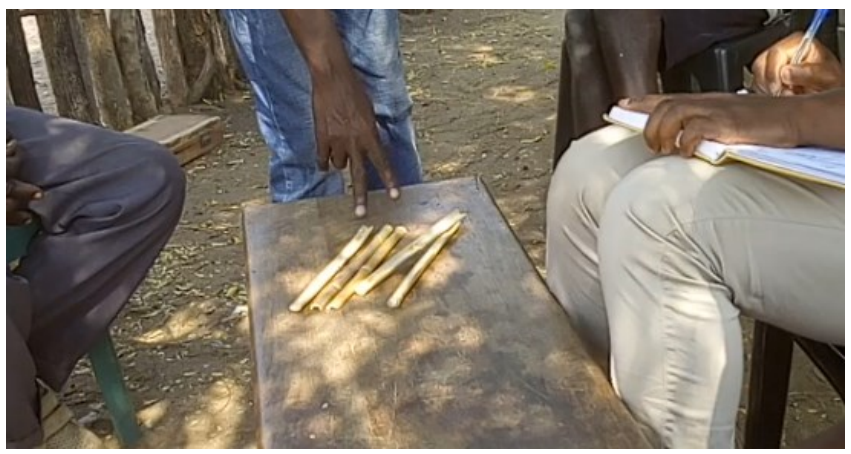

Figura 7. Praticando com o jogo Mbetete. Fonte: Autores (2021)

Quadro 2: Disposição das peças no chão e o equivalente número de pedrinhas livradas

\begin{tabular}{|l|l|l|l|l|}
\hline Nr de lançamento & Peças abertas & Peças fechadas & Par & $\begin{array}{l}\text { Pedras } \\
\text { cedidas }\end{array}$ \\
\hline $1^{\circ}$ lançamento & 0 & 5 & $(0 ; 5)$ & 10 \\
\hline $2^{\circ}$ lançamento & 1 & 4 & $(1 ; 4)$ & 0 \\
\hline $3^{\circ}$ lançamento & 2 & 3 & $(2 ; 3)$ & 3 \\
\hline $4^{\circ}$ lançamento & 3 & 2 & $(3 ; 2)$ & 2 \\
\hline $5^{\circ}$ lançamento & 4 & 1 & $(4 ; 1)$ & 0 \\
\hline $6^{\circ}$ lançamento & 5 & 0 & $(5 ; 0)$ & 5 \\
\hline
\end{tabular}

Fonte: Autores (2021) adaptado do discurso do senhor Pita Jhon Tembo 


\subsection{Possibilidades do uso do jogo Mbetete para introdução a probabilidades}

Nesta seção apresentamos uma organização didática (sequência de atividades de estudo) com a qual se pretende ensinar os conceitos básicos e inicias sobre probabilidade, através das praxeologias que se observam ou exploram na pratica com o jogo Mbetete. Trata-se de apresentar uma proposta de circulação de praxeologias sobre o jogo Mbetete ao ensino de probabilidade, isto é, uma organização didática que possibilite que conhecimentos sobre probabilidade possam emergir a partir do contato e pratica com um objeto do contexto sociocultural não eurocentralizado/ocidental.

Ao descrevermos a organização didática, serão explicitadas as praxeologias esperadas na implantação das atividades, lembrando que, são praxeologias que no contexto pratico com os alunos podem ou não emergia, de acordo como vai ser a relação pessoal dos alunos ao jogo Mbetete. Supõe-se que, a partir das praxeologias produzidas nessa relação e por meio da ajuda do professor, os alunos possam ou não alcançar uma relação pessoal com os conceitos básicos e inicias sobre probabilidade. A organização será estruturada em três atividades de estudo, cada uma delas envolvendo algumas etapas.

Atividade 1: Apresentação do jogo aos alunos. O objetivo dessa atividade é familiarizar os alunos com o jogo, apresentando-o desde a sua gênese, o seu contexto social às práticas ou regras do jogo. Trata-se de um trabalho de devolução segundo o qual "o professor colocara o jogo a disposição do aluno com objetivo de provocar uma interação suficientemente rica e que permita ao aluno o desenvolvimento autônomo. Portanto, trata-se em última instancia do ato pelo qual o professor faz o aluno aceitar a responsabilidade de uma situação de aprendizagem (adidática) ou de um problema aceitando as consequências dessa transferência" (ALMOULOUD, 2010, p. 34-35).

Pode-se destacar que, aqui, o professor ao apresentar o jogo, vários elementos culturais sobre $\circ$ mesmo poderão emergir. Depois que tiver apresentando o jogo, o professor deverá dividir os alunos em grupos de pelo menos 5 alunos e deixá-los que pratiquem o jogo por algum tempo, entre 10 a 15 minutos. 
Aqui, os alunos poderão jogar livremente, compreendendo a partir da pratica, as regras do jogo.

Atividade 2: No segundo momento, o professor solicitará aos alunos que façam algumas jogadas em seus grupos, em um tempo estimado de 5 minutos e, na medida em que vão jogando, registem em uma tabela cada par de peças (abertas; fechadas), indicando também, o número de pedras que cedeu ao adversário em cada jogada efetuada. Em seguida, após as jogadas terminarem em cada grupo, o professor fará determinadas questões dirigidas a cada grupo. Trata-se primeiramente de três questões, que permitiram o aluno levantar algumas insinuações em relação aos registros de dados que efetuou na medida que ia jogando. O objetivo desta atividade é identificar a noção de espaço amostral, as circunstancias e chance em que um jogador ganharia em um único lançamento, conceitos que dão vida inicial a noção de probabilidade.

Q.1. - Olhando os registros que você tem sobre os pares de peças abertas e fechadas, quais e quantos pares você acha que podem ser formados em um lançamento do jogo? Associe a cada par o número de pedrinhas que deve se livrar.

Q.2. - Em um único lançamento, em que circunstancias você poderia ganhar ० jogo?

Q.3. - Nestas circunstancias, quais seriam as suas chances de vencer no jogo em um único lançamento?

Este questionamento, suscitaria aos alunos investigar as possibilidades de pares ordenados que podem ser formados. A resposta esperada para Q.1. é que consigam identificar 6 pares, que iriam compor o seguinte espaço amostral em um único lançamento: $S=\{(0 ; 5),(1 ; 4),(2 ; 3),(3 ; 2),(4 ; 1),(5 ; 0) . \quad$ A esse espaço amostral, pelas regras do jogo, certamente que saberiam dizer que está associado aos seguintes números de pedrinhas a descartar $S^{\prime}=\{10 ; 0 ; 3 ; 2 ; 0 ; 5\}$.

Como se sabe, um jogador vence o jogo quando tiver se desfeito de todas as pedrinhas, neste caso, se tiver se livrado das 10 pedrinhas em sua posse. Com esta indicação, que constitui a regra para determinar o vencedor do jogo, facilmente se pode deduzir a partir dos resultados de $S^{\prime}$ que, em um único 
lançamento só é possível vencer o jogo se as peças do Mbetete tiverem caídos todas na posição fechada, que resultaria no ponto amostral $(0 ; 5)$, correspondente ao evento unitário $A=\{(0 ; 5)\}$. Este ponto amostral $(0 ; 5)$, corresponde então a 10 pedrinhas que o jogador deve se livrar delas, entregando ao adversário. Com este detalhe, a Q.2. se daria por respondida.

A resposta da Q.2. propositadamente levaria a resposta da Q.3., porém, os alunos seriam convidados antes a visitar os conceitos de percentagem da chance de um evento. Trata-se de um passeio pelas mídias e meios, uma importante dialética na implementação de atividades de estudo e pesquisa, para busca incessante de resposta aos questionamentos.

Neste caso, a resposta esperada é que os alunos identifiquem que a percentagem da chance de ocorrência de determinado evento é dada pela divisão entre o número de vezes que esse evento ocorre pelo número de possibilidades que podem ocorrer em um experimento. Para o caso concerto da questão, teríamos que, a chance de vencer o jogo em um único lançamento seria de $\frac{1}{6} \times 100 \%=16, \overline{6} \%$.

Atividade 3: desvendando os conceitos básico. Com base nos elementos de discussão apresentados na atividade 2, nesta fase, o professor começaria com o processo de institucionalização dos conceitos apresentados ao longo da discussão, um processo pelo qual "são fixados convencionalmente e explicitamente o estatuto cognitivo do saber, fazendo tornar o novo conhecimento parte do patrimônio matemático da classe" (ALMOULOUD, 2010, p. 40). Neste caso, começaria por recuar nas questões e respostas apresentadas anteriormente, a partir do qual começaria explicando aos alunos o significado conceitual das respostas que eles dariam as questões colocadas.

Portanto, apresentamos apenas uma amostra de como se pode utilizar o Mbetete para gerar aprendizagem de objetos matemáticos, colocando os alunos a trabalharem com suas próprias praticas, de modo que possam entender e ver o sentido desses objetos socioculturais não eurocêntricos em seu percurso formativo.

O professor pode sugerir outras atividades, para explorar mais possibilidades e entendimento do jogo. Por exemplo, antes da institucionalização, pode fazer 
outros questionamentos, que possam ir além de um lançamento das peças, digamos, estudar o comportamento das pedrinhas cedidas, que levem o jogador a ganhar o jogo em mais de um lançamento. Certamente, isso provocaria mais tenções e discussões e, mais elementos sobre probabilidade e outras áreas do conhecimento matemático poderão emergir.

\section{Considerações finais}

A inclusão de conteúdo de interesse local no ensino ainda é um desafio, embora hoje os currículos já preveem, por exemplo em Moçambique que $20 \%$ do tempo de aula das disciplinas possam ser dedicadas ao conteúdo de interesse local. No Brasil, as leis 10.639/2003 e 11.645/2008 já prevê que os currículos passam trabalhar conteúdos ligados a história e cultura dos povos africanos, afro-Brasileiro e indígenas. Todavia, pensa-se ainda hoje que há algumas limitações na implementação das mesmas, fato que neste artigo, propomos alternativas didáticas (a nível teórico e prático), que possam primeiramente possibilitar questionar o que está posto no currículo, segundo possibilitar a análise e difusão dos saberes oriundos de conteúdos de interesse local, que são renegados por práticas de ensino que fomentam o racismo epistemológico institucional, ao renegarem que outros saberes não tenham legitimidade cientifica para participarem do processo de construção do conhecimento cientifico.

Diferentes movimentos, especificamente ligados aos estudos de grupos da Modernidade/Colonialidade/Decolonialidade, ora liderados principalmente por pesquisadores sociais como Edgard Lander, Enrique Dussel, Walter D. Mignolo, Arturo Escobar, Aníbal Quijano, etc., tem apontado e levantado discussões sobre práticas de dominação e descriminação implícitas na modernidade, que se caracterizam por apresentarem-se poderosas e hegemônicas, alimentadas em uma matriz sobrevivente colonial (LANDER, 2005). Estas formas de dominação e descriminação também se apresentam na educação/ensino, especificamente a nível epistemológico-institucional, o que suscita uma ampla discussão que permita aos intervenientes educacionais levantar e questionar as formas discriminatórias de acesso ao saber no ensino e propor estratégias e/ou ações de desobsessão a 
naturalização do pensamento moderno eurocêntrico colonial, como forma única de pensar e produzir a ciência.

É sobre essa descriminação a outras sabedorias e a obsessão pelo pensamento moderno eurocêntrico ocidental enquanto pensamento único para produção e acesso ao saber cientifico, que se propõe ações de resistência e denuncia a discriminação e o racismo epistemológico, que nesse artigo discutimos por meio da didática da matemática, como questionar e denunciar praticas estas praticas dilatórias, que se manifestam nos nossos currículos e que caminhos podemos seguir para neutralizar e levar ao sistema escolar estes conhecimentos que sobejamente tem sido retirado o seu lugar na produção do conhecimento. Apresentamos assim, uma proposta que visa possibilitar ruptura a estes modos operantes no processo de difusão do conhecimento (matemático), que é uma caraterística que pretende ser de dominação política, cultural, acima de tudo, epistemológica eurocentrista no ensino.

Para levantar esse diálogo no campo da didática da matemática (DM), que é um dialogo meramente decolonial, nos alicerçamos da Teoria Antropológica do Didático (TAD), a partir da abordagem ecológica do saber, que é uma metodologia dentro da TAD que possibilita questionar o currículo no sentido de que, se possa investigar e analisar as praxeologias que nelas estão ou não estão postas, isto é, o que existiu, existe e não existe e porquê, sobre os objetos de saber em seu ambiente conceitual. Estes questionamentos, direcionam-nos a um caminho que busca desvendar as práticas delatórias que estão nos currículos sobre o racismo epistemológico institucional.

Estas denúncias, permitem então, que os didatas comprometidos com a implementação de conteúdo de currículo local e das leis 10.639/2003 e 11.645/2008, possam se reposicionar, e estudar possibilidades que vissem a resistências a estas práticas, que descriminam saberes não eurocentrados. Entre as possibilidades que propõe acções para resgatar e levar as práticas socioculturais não eurocêntricas ao sistema de ensino, encontramos na didática da matemática, por via da TAD, a abordagem de circulação de praxeologias, que permitem, que praxeologias renegadas sejam analisadas e transpostas ao processo de ensino e 
aprendizagem de disciplinas diversas.

Assim, com essa abordagem, esperamos que praxeologias que não vivem em instituições escolares relegadas ao primitivismo, possam ser deslocadas a sala de aulas, em particular e tomar o lugar na produção de conhecimentos que produzem sentidos e afeto aos alunos.

Deste modo, consideramos que o didata de matemática, consegue entrar nesta luta de resistência ao pensamento moderno colonial eurocêntrico/ocidental, propondo alternativas que possibilitem que outros saberes que não se fundamentam dentro do pensamento moderno colonial eurocêntrico/ocidental participem ativamente na produção de saberes científicos e escolares, permitindo a implementação efetiva do conteúdo de currículo local e das leis 10.639/2003 e $11.645 / 2008$.

\section{Referências bibliográficas}

ALMEIDA, Silvio. Racismo Estrutural. São Paulo: Sueli Carneiro; Pólen, 2019.

ALMOULOUD, Saddo Ag. Teoria Antropológica do Didático: metodologia de análise de materiais didáticos. Revista Ibero-americana de educação matemática. N. 42. Noviembre de 2015, p. 09-34. ISSN: 1815-0640

BERNARDINO-COSTA, Joaze; GROSFOGUEL, Ramón. Decolonialidade e perspectiva negra. Revista Sociedade e Estado, v. 31, n. 1, p. 15-24, 2016.

BOYER, C. B. Egipto. In: História da Matemática. Tradução: Elza Furtado Gomide. São Paulo: Edgard Blücher, 1974. p. 7 - 17.

BRAGATO, Fernanda Frizzo; CASTILHO, Natalia Martinuzzi. A importância do póscolonialismo e dos estudos descoloniais na análise do novo constitucionalismo latino-americano. In: O pensamento pós e descolonial no novo constitucionalismo latinoamericano. [recurso eletrônico] / organizadores: Eduardo Manuel Val, Enzo Bello. - Caxias do Sul, RS: Educs, 2014, pp. 11 - 25. Disponível em: https://www.ucs.br/educs/livro/pensamento-pos-e-descolonial-no-novoconstitucionalismo-latino-americano//. Acesso em: 23 de junho de 2021.

BRASIL. Lei Federal n 10.639/03, de 09 de janeiro de 2003. Brasília - DF.

BRASIL. Lei $n^{\circ} 11.645$ de 10 de março de 2008. altera a lei $n^{\circ} 9.394$, de 20 de dezembro de 1996, modificada pela lei n. ${ }^{\circ} 10.639$, de 9 de janeiro de 2003, que estabelece as diretrizes e bases da educação nacional, para incluir no currículo 
oficial da rede de ensino a obrigatoriedade da temática "história e cultura afrobrasileira e indígena". Brasília, 11 de março de 2008.

CASSINI, Sérvio. Conceito de ecologia, nicho e habitat. Disponivel em: http://www.inf.ufes.br/ neyval/Gestao_ambiental/Tecnologias_Ambientais2005/E cologia/CONC_BASICOS_ECOLOGIA_V1.pdf

CASTELA, Corine. Un enfoque ecológico de lo didáctico. Escola de Altos Estudos Campo Grande-Brasil 3 de abril 2019. Disponível em: https://irem.pucp.edu.pe/wpcontent/uploads/2019/08/Conference_ecologie_Castela.pdf.

CASTELA, Corine. When praxeologies move from an institution to another one: an epistemological approach of boundary crossing. In Göller r, R., Biehler, R., Hochmuth, R., Rück, H-G. (Eds.). Didactics of Mathematics in Higher Education as a Scientific Discipline - Conference Proceedings, pp. 418-425, 2017. Disponível em: http://nbn-resolving.de/urn:nbn:de:hebis:34-2016041950121.

CONCEIÇÃO, Luciano da. Moçambique: Construções criativas com chapas de zinco. Inhambane: DW, 2019. Disponível em: https://www.dw.com/pt002/mo\%C3\%A7ambique-constru\%C3\%A7\%C3\%B5es-criativas-com-chapas-dezinco/g-50231235

CHEVALLARD, Y. A Teoria Antropológica do Didático face ao Professor de Matemática. In: ALMOULOUD, S. A.; FARIAS, L.M.S; HENRIQUE, A. Teoria Antropológica do Didático: Princípios e fundamentos. Curitiba: CRV, 2018a.

CHEVALLARD, Y. La TAD et son devenir : rappels, reprises, avancées. Dans G. Cirade et al. (Éds), Évolutions contemporaines du rapport aux mathématiques et aux autres savoirs à l'école et dans la société, pp. 27-65, 2017. Disponível em: https://citad4.sciencesconf.org

CHEVALLARD, Yves. L'analyse des pratiques enseignantes en théorie anthropologique du didactique. Recherches En Didactique Des Mathématiques, 19(2), 221-266, 1999. https://revue-rdm.com/1999/l-analyse-des-pratiques/

CHEVALLARD, Yves. Les processus de transposition didactique et leu théorisatin. In. ARSAC G., CHEVALLARD, Y., et al, (org.). La transposition didactique à l'épreuve. Grenoble: La Pensée sauvage, 1994. p. 135-180. Disponível em: http://yves.chevallard.free.fr/spip/spip/article.php3?id_article=114

CHEVALLARD, Yves. Prólogo: Uma Ruptura Epistemológica em ato. In: ALMOULOUD, S. A.; FARIAS, L.M.S; HENRIQUE, A. Teoria Antropológica do Didático: Princípios e fundamentos. Curitiba: CRV, 2018a.

CUNHA, Lázaro. Contribuição dos povos africanos para o conhecimento científico e tecnológico universal. Disponível em: http://smec.salvador.ba.gov.br/documentos/contribuicao-povos-africanos.pdf. 
DIAS, G. H. et al. A importância de contos na compreensão da diversidade cultural. In: XVI ENCONTRO LATINO AMERICANO DE INICIACAO CIENTIFICA. Paraíba: 2012.

DOUADY, Régine. Jeux de cadres et dialectique outil-objet. Recherches En Didactique Des Mathématiques. França, Vol. 7, no 2, p. 5-31. 1986. Disponível em: https://revue-rdm.com/1986/jeux-de-cadres-et-dialectique/.

ASANTE, M. K. Raça na Antiguidade: na verdade, provém da África. CapoeiraHumanidades e Letras, v. 1, n. 3, p. 105-113. 2015. Título original Race in Antiquity: truly out of Africa. Tradução de Fernando Lopes Tomé.

ESTERMANN, J.; TAVARES, M.; GOMES, S. (2017). Interculturalidade crítica e decolonialidade da educação superior: para uma nova geopolítica do conhecimento. Laplage em Revista (Sorocaba), vol.3, n.3, set.-dez, p.17-29. ISSN:2446-6220. DOI: https://doi.org/10.24115/S2446-6220201733375, p.17-29

EVES, Howard. A matemática Babilônica e Egípcia. In: . Introdução à história da matemática. Tradução de Hygino H. Domingues. 5 a ed. Campinas, sp: Editora da Unicamp, 2011 . p. 57 - 89.

GERDES, Paulus. Etnogeometria: Cultura e o despertar do pensamento geométrico. $2^{a}$ Edição. Boane: ISTEG, 2012.

GIRALDO, Victor. Alargando Sentidos: o que queremos dizer por decolonizar currículos em matemática? RIPEM, v. 11, n.2, 2021 pp. 01-08. Disponível em: http://sbem.iuri0094.hospedagemdesites.ws/revista/index.php/ripem/article/view/ $2755 / 1905$.

GIRALDO, Victor. Decolonialidade e Educação Matemática. Rio de Janeiro: Laboratório de Ensino de Matemática - Curso de Licenciatura em Matemática do IFRJ, campus Nilópolis. Youtube. 2020a. Disponível em: https://www.youtube.com/watch?v=S79EDxBlhJk\&t=2140s.

GIRALDO, Victor. Que matemática para a formação de professores? Por uma matemática problematizada. Anais do XIII Encontro Nacional de Educação Matemática, Sociedade Brasileira de Educação Matemática. Cuiaba/MT: 2019. Disponível em: https://www.sbemmatogrosso.com.br/xiiienem/anais.php.

GIRALDO, Victor; MATOS, Diego; QUINTANEIRO Wellerson. Entre epistemologias hegemônicas e sabedorias outras: a matemática na encruzilhada. Revista Latinoamericana de Etnomatemática. Vol. 13, No. 1, de enero-abril de 2020b.

INDE/MINED. Plano Curricular do Ensino Básico (PCEB) - Objectivos, Politicas, Estrutura, Plano de Estudos, e Estratégias de Implementação. Maputo: INDE/MINED - Moçambique, 2008. 
INDE/MINED. Plano Curricular do Ensino Secundário Geral (PCESG) - Documento Orientador, Objectivos, Política, Estrutura, Plano de Estudos e Estratégias de Implementação. Maputo: Imprensa Universitária da UEM, 2007.

LANDER, Edgardo (org). A colonialidade do saber: eurocentrismo e ciências sociais. Perspectivas latino-americanas. Colección Sur Sur, CLACSO, Ciudad Autónoma de Buenos Aires, Argentina. setembro 2005. Disponível em: https://ufrb.edu.br/educacaodocampocfp/images/Edgardo-Lander-org-AColonialidade-do-Saber-eurocentrismo-e-ciC3AAncias-sociais-perspectivaslatinoamericanas-LIVRO.pdf

MOÇAMBIQUE. Boletim da República. Resolução n 12/97 de 10 de Junho 1997. Aprova a Política Cultural e Estratégia de sua Implementação. Maputo: Imprensa Nacional, 1997.

ODUM, Eugene. Fundamentos de Ecologia. $6^{a}$ edição. Editora da Calouste Gulbenkian, 1988.

PAPERT, Seymour. A Máquina das Crianças: Repensando a Escola na Era da Informática. Porto Alegre: Artmed, 2008.

PIVA, Elisabete do Carmo Dal. Diversidades: Todos Somos Um. EDUCERE - XIII Congresso Nacional de Educação - PUCPR, IV Seminário Inter. de Representações Sociais, Subjetividade e Educação - SIRSSE e VI Seminário Internacional Profissionalização Docente (Cátedra Unesco), de 28 a 31 de agosto de 2017. Disponível em: https://educere.bruc.com.br/arquivo/pdf2017/25829_12355.pdf.

QUIJANO, Aníbal. 'Colonialidad y modernidad/racionalidad', Perú Indíg. 13(29), pp. 11-20, 1992.

ROQUE, Tatiana. Matemáticas na Mesopotâmia e no antigo Egito. In: . História da Matemática: Uma visão crítica, desfazendo mitos e lendas. $\overline{l a}$ ed. Rio de Janeiro: Editora Zahar; 2012.

SANTOS, V. M. Notas desobedientes: decolonialidade e a contribuição para a crítica feminista à ciência. Psicologia \& Sociedade, 30, e200112 1. 2018.

SILVA, Getúlio Rocha. Uma proposta didática para descolonizar o "teorema de Pitágoras" em cursos de licenciaturas em matemática. In: Descolonizando saberes: a Lei 10.639/2003 no ensino de ciências. Organizadoras: Bárbara Carine Soares Pinheiro, Katemari Rosa. São Paulo: Editora Livraria da Física, 2018. - (Coleção culturas, direitos humanos e diversidade na educação em ciências).

SILVA, Getúlio Rocha; FARIAS, Luiz Marcio Santos. Caminhos para uma descolonização Epistemológica: contribuições para a descolonização da Didática da Matemática. In: Trajetórias Descolonização da Escola: O enfrentamento do racismo de ciências e tecnologias. Organizadoras/es: Anna Maria Canavarro Benite; Marysson Jonas Rodrigues Camargo; Nicéa Quintino Amauro. Belo 
Horizonte: Ndndyala, 2020.

ZALAMENA, Juliana Costa Meinerz. Colonização e qualidade democrática na África segundo o Democracy Index. Sinais, n. 22/1 Jan-Jun 2018a, Vitória-Brasil. S ISSN: 1981-3988. Disponível em: https://periodicos.ufes.br/sinais/article/view/17572.

ZALAMENA, Juliana. Colonização e qualidade democrática: apontamentos com base no democracy index. Revista Eletrônica de Ciência Política, vol. 9, n. 1, 2018b. ISSN 2236-451X.

Disponível

em:

https://revistas.ufpr.br/politica/article/view/54493/35206.

\section{Nota de Agradecimentos}

Apraz-nos nesse artigo, endereçar os nossos agradecimentos ao Professor Pita Jhon Tembo, especialista em jogos tradicionais, a quem nos recebeu no distrito de Changara, localidade de N'Temangau e nos orientou na realização do trabalho de pesquisa com os jogos tradicionais. Agradecimentos extensivos vão ao Chefe da Localidade o senhor Ernesto Mofate Patrício, que recebeu e autorizou a equipe de pesquisa a realizar suas atividades nesta localidade. 